\title{
Perspectivas teóricas sobre Movimentos Sociais
}

\author{
Theoretical perspectives on Social Movements \\ Perspectivas teóricas sobre los Movimientos Sociales
}

Recebido: 22/07/2021 | Revisado: 25/07/2021 | Aceito: 26/07/2021 | Publicado: 02/08/2021

\author{
Andreza Aparecida Franco Câmara \\ ORCID: https://orcid.org/0000-0001-8761-2197 \\ Universidade Federal Fluminense, Brasil \\ Universidade Federal Rural do Rio de Janeiro, Brasil \\ E-mail: andrezafranco@id.uff.br \\ Paulo Brasil Dill Soares \\ ORCID: https://orcid.org/0000-0003-0724-8271 \\ Universidade Federal Fluminense, Brasil \\ E-mail: paulobrasildillsoares@id.uff.br \\ Alessandra Dale Giacomin Terra \\ ORCID: https://orcid.org/0000-0003-3311-121X \\ Universidade Federal Fluminense, Brasil \\ E-mail: alessandraterra@id.uff.br
}

\begin{abstract}
Resumo
O presente artigo investigará as novas teorias contemporâneas dos movimentos sociais, sem perder de vista o debate sobre as teorias clássicas, localizando seu surgimento histórico, ideias centrais e a teoria dos novos movimentos sociais. Parte-se do pressuposto que os movimentos sociais, a partir da escola teórica vinculada, abordam questões chaves na modernidade com viés econômico, político e social. Para tanto, adotou-se como metodologia qualitativa, por meio de revisão de literatura.
\end{abstract}

Palavras-chave: Ações coletivas; Movimentos sociais; Participação social.

\begin{abstract}
This article will investigate the new contemporary theories of social movements, without losing sight of the debate on classical theories, locating their historical emergence, central ideas and the theory of new social movements. It is assumed that social movements, from the linked theoretical school, address key issues in modernity with an economic, political and social bias. Therefore, it was adopted as a qualitative methodology, through a literature review.
\end{abstract}

Keywords: Collective actions; Social movements; Social participation.

\section{Resumen}

Este artículo indagará en las nuevas teorías contemporáneas de los movimientos sociales, sin perder de vista el debate sobre las teorías clásicas, ubicando su surgimiento histórico, las ideas centrales y la teoría de los nuevos movimientos sociales. Se asume que los movimientos sociales, desde la escuela teórica vinculada, abordan temas clave de la modernidad con un sesgo económico, político y social. Por tanto, se adoptó como metodología cualitativa, a través de una revisión de la literatura.

Palabras clave: Acciones colectivas; Movimientos sociales; Participación social.

\section{Introduçãa}

Embora o tema movimentos sociais seja estudado por diversos autores europeus e americanos, sob a ótica da ação coletiva enquanto relação socialmente conflitiva, no contexto da América Latina se faz necessário uma mudança de perspectiva em relação ao uso dessas duas correntes teóricas explicativas dos movimentos sociais e seus principais marcos de luta.

No século XIX e no início do século XX, o modelo predominante de movimento social na sociedade industrial era o do movimento operário. Durante as décadas de 1960 a 1980, enquanto grande parte dos países da Europa Ocidental e da América do Norte vivenciaram importantes ampliações das pautas dos movimentos sociais, sendo que as bandeiras variavam desde questões envolvendo gênero, direitos civis, ecológica, autonomia regional e paz; outros países em desenvolvimento buscavam nos movimentos sociais (tradicionais) as soluções para a libertação nacional e a democratização. 
Por seu turno, a presente discussão pretende examinar as teorias contemporâneas dos movimentos sociais, situando seu surgimento histórico, ideias centrais. Parte-se da hipótese de que os movimentos sociais, a partir da escola teórica vinculada, abordam questões chaves na modernidade com viés econômico, político e social.

Os autores clássicos examinam os movimentos sociais a partir da noção de ciclos evolutivos nos quais seu surgimento, amadurecimento e difusão se dariam através de um processo de comunicação decorrente de rumores, conversas, propagação de ideias, ativação de redes de conhecimentos etc. Dessa intensa comunicação estabelecida, eclodiria a insatisfação com as questões postas e geraria a adesão aos movimentos sociais como uma resposta psicológica ${ }^{1}$ às crises vividas durante a vigência da sociedade industrial. Esses componentes, vinculados aos princípios homogêneos impostos eram o estopim para a emergência de movimentos sociais.

Em relação aos sistemas políticos, os movimentos sociais não seriam capazes de influenciar ou alterar a lógica de funcionamento desses sistemas, devido à sua essência espontânea e fluída; somente os partidos políticos, grupos de interesses e alguns líderes teriam tal capacidade, aparentemente democrática, de mudarem os sistemas estabelecidos, constituindo um verdadeiro ativismo da minoria.

Os comportamentos coletivos extra institucionais, de conotação ideológica, eram vistos como uma tentativa de burlar a ordem democrática vigente e ameaçaria o consenso estabelecido na sociedade civil. Diante dessa perspectiva, é possível dividir o estudo sobre os movimentos sociais em cinco ciclos, que tratam da teoria da ação coletiva, e em três deles os movimentos sociais enquanto conceito-chave.

\section{Metodologia}

Trata-se de uma revisão bibliográfica, enquanto coleta de dados secundária (Lakatos \& Marconi, 2004), com o recorte teórico da Sociologia dos Movimentos Sociais, desenvolvida por meio de metodologia qualitativa, na qual utilizou-se como método de abordagem dedutivo-hipotético (Nevado, 2008) e como método de procedimentos o histórico, através de um mapeamento dos principais livros, artigos e trabalhos científicos (Pereira, A. S., Shitsuka, D. M., Parreira, F. J. \& Shitsuka, R, 2018), em que se buscou analisar as principais teorias contemporâneas sobre movimentos sociais.

\section{Resultados e Discussão}

\section{A Escola de Chicago e o Interacionismo Simbólico}

$\mathrm{Na}$ Escola de Chicago e alguns interacionistas simbólicos, que estudam o comportamento coletivo e dos movimentos sociais, o pressuposto dessa corrente de pensamento seria a constituição da sociologia como disciplina de investigação científica e, que apresentaria como um de seus objetivos a análise do comportamento dos indivíduos e grupos de pessoas a partir de expectativas comuns, e o surgimento dos movimentos sociais em realidades não-estruturadas.

A Escola de Chicago entende que os movimentos sociais são frutos da mudança social, provocada pelo interesse particular de seus mentores e sua percepção sobre o "desenvolvimento da comunidade" e a respeito do processo de participação e educação "para o povo" (Gohn, 2000, p. 27).

A crítica feita ao paradigma interacionista simbólico sobre o tema movimentos sociais reside no fato de que tal teoria enfatiza aspectos individuais, como emoção, sentimento de solidariedade, comportamento expressivo e comunicação, atribuindo aos líderes um papel central na interação com a sociedade, pois aqueles deveriam apresentar atitudes criativas e capazes de mudar e reformar o meio social. E a sociologia, enquanto ciência, forneceria instrumentos para essa interação e

${ }^{1}$ Gohn (2000) informa que para essas correntes a reação psicológica dos indivíduos diante das mudanças era resultado de um comportamento irracional, fruto da desorganização social advinda após rápidas mudanças sociais. 
mudança sociais. Na verdade, aqueles que detivessem o conhecimento científico útil seriam responsáveis pela mudança de rumo e a criação de novas instituições.

A participação ativa e a interação eram pontos importantes na militância dos líderes. Atos voluntários e ações espontâneas ganhavam espaço nas agendas das lideranças que tinham obrigações com o grupo.

O conflito era algo natural e inevitável como resultado das experiências e culturas dos diferentes membros que compunha o grupo, cabendo ao líder a função "messiânica" de proporcionar a melhor solução para todos. Desse modo, os movimentos sociais seriam o resultado dos conflitos gerados entre as multidões².

As mudanças sociais, segundo o paradigma interacionista, seriam o ápice entre a eficiência dos líderes em controlar o grupo social e a autodeterminação dos membros desse grupo. O ponto negativo desse pensamento reside no fato de que os líderes, por vezes, não conseguem controlar os movimentos. A solução, portanto, seria constituir novas lideranças que consolidassem mecanismos educativos para a resolução das crises.

\section{As teorias sobre a sociedade de massas}

A segunda corrente desenvolveu-se a partir das teorias sobre a sociedade de massas ${ }^{3}$, tendo como principais representantes Erich Fromm (1941), Eric Hoffer (1951) e William Kornhauser (1959). Dentre as principais ideias defendidas encontram-se que, os comportamentos coletivos são resultados de ações desconectadas das condutas tradicionais, resultado da anomia e de privações vividas pelo coletivo. Assim, a exclusão de indivíduos política, social e economicamente acarretaria reações através de sua atuação política "desviante" em relação aos valores tradicionais da sociedade.

Os autores dessa corrente buscaram nos trabalhos de Gustave Le Bon (1895) a atuação dos movimentos sociais, que via nos motins da Revolução Francesa um comportamento cego e irracional das massas, concluindo que os sujeitos são capazes tanto de atos de heroísmo quanto de barbárie, uma vez aglutinados pelo poder da massa podem perder o uso da razão crítica e serem levados a praticar atos violentos. Associados aos pensamentos de Le Bon (1895) e analisando o fenômeno do fascismo, esses pensadores estudavam os movimentos não democráticos, com o viés da alienação das massas, perda do controle e da influência das elites culturais.

Os movimentos sociais não conseguiriam a emancipação da massa, pois em uma sociedade dominada por tecnologias complexas e o despreparo do coletivo para obter soluções políticas racionais só restaria a perda do status econômico e do acesso ao poder político.

\section{A perspectiva sociopolítica da ação coletiva}

Seymour Martin Lipset (1950) e Rudolf Heberle (1951) abordaram a teoria da ação coletiva por meio da perspectiva sociopolítica. Influenciados pela conjuntura política internacional resultante da Guerra Fria e do surgimento de movimentos com conotação ideológica, esses autores articulam no sentido de que as classes sociais e as relações sociais de produção deveriam ser categorias a ser estudadas como comportamentos coletivos do tipo político-partidário.

Seymour Martin Lipset (1950) analisa categorias como poder político e mobilização partidária e sua influência no comportamento dos eleitores para entender as mudanças provocadas na América Latina nos anos 50.

Heberle (1951), por sua vez, visando compreender o fenômeno do nazifascismo, as revoluções e conflitos entre nações, publica o livro Movimentos sociais: uma introdução à sociologia política (1951). Sua proposta era comparar e

\footnotetext{
${ }^{2}$ A noção de multidão é composta por um conjunto de singularidades não-representáveis. A multidão é um conceito de classe, vinculada a produção em movimento. Sob o enfoque temporal, a multidão é explorada pela produção; já sob a perspectiva espacial, a multidão é ainda procurada, na medida em que constitui a sociedade produtiva e a cooperação social para a produção. (NEGRI, 2009, p. 19).

${ }^{3}$ A teoria da sociedade de massas foi difundida no período dos 1930 e 1940, no auge da crise econômica vivida pela quebra da Bolsa de Valores de Nova Iorque, ocasionada pelo declínio da esfera pública, pela manipulação da vida política e pela erosão da solidariedade moral, derivados do ambiente cético da industrialização, mais tarde, dominada pelo então fantasma da guerra.
} 
sistematizar os movimentos sociais através dos conceitos de coletivo social e da relação comunidade-sociedade no campo da sociologia compreensiva.

Heberle via nos movimentos um tipo de grupo social com estrutura particular que fugia da identificação de Lorenz Von $\operatorname{Stein}^{4}$ (1842), para quem os movimentos se restringiam ao universo da classe operária na sociedade industrial. Para aquele autor, os movimentos sociais eram grupos corporativos de interesses multinacionais, que apresentavam consciência, sentimento de pertencimento, solidariedade e identidade grupal, com compromissos coletivos e ideologias afins.

Heberle (1951) considerava que os movimentos sociais eram o resultado de vontade política do grupo, que buscavam nas elites políticas treinamento e recrutamento para alcançar seus objetivos. Desse modo, os movimentos eram o resultado do descontentamento dos indivíduos com a ordem social vigente e sua meta seria a mudança dessa ordem. $\mathrm{O}$ autor destaca a atuação das lideranças no contexto geopolítico, tendo como cerne o binômio integração versus desintegração social.

\section{A teoria do sistema social}

A teoria do sistema social é estudada por Parsons (1951), que propõe a existência de quatro dimensões básicas no sistema de ação, sendo elas: adaptação, consecução de metas, manutenção de padrões e integração.

Esses elementos combinados formam valores centrais, normas, papéis, estruturas, função-equilíbrio e diferenciação estrutural, não havendo, em sua teoria, espaço para a emergência de sujeitos/atores sociais, mas do sistema social através de ações individuais. O sujeito parsoniano é um utilitarista, cujas metas são claramente estabelecidas e cujos instrumentos econômicos e culturais disponíveis visam satisfazer suas necessidades.

A aplicação da teoria do sistema de ação social aos movimentos sociais deu origem à concepção funcionalista, tendo como ideia central a de que os comportamentos coletivos geram os movimentos decorrentes de períodos de inquietação social, incertezas, impulsos reprimidos, ações frustradas, mal-estar e desconfortos sociais, associados ao descontrole e a desintegração do costumes sociais; tais acontecimentos levariam os indivíduos a reagirem, organizando-se em movimentos que atuariam fora do padrão promovido pelos sujeitos históricos.

A ocorrência sistemática de tal situação, deixava claro que aquela sociedade era instável e desagregada, pois o surgimento de grupos alienados e plenos de tensões seriam quase inexistentes em um grupo social controlado. Dentre as categorias utilizadas pelos autores do funcionalismo encontram-se anomia/disnomia (Durkheim, 1897) e organização/desorganização (Merton, 1949).

O conceito-chave da teoria social é a mudança no comportamento individual, mesmo que esse sujeito se encontre integrado a uma instituição. Os movimentos atuariam num cenário de irracionalidade em oposição à ordem vigente. Portanto, mudança social era sinônimo de sociedade desorganizada, de colapso no sistema social e de desvio social.

Questões como "isolamento social", "descontentamento", "desajuste", "descontrole" reaparecem com viés antropológico (Tönnies, 1996), a respeito dos costumes sociais. Assim, o aparecimento de um movimento social teria como pano de fundo o desbloqueio estrutural, isto é, o rompimento nas regras da estrutura social, que impedem e repelem as fontes de descontentamento; adicionado a comunicação em rede dos descontentes e a esperança de que a ação proposta seja eficaz para mudar o status vigente, dotada de forte ideologia no novo sistema.

Os movimentos sociais, na teoria funcionalista de Parsons (1951), apresenta uma tênue separação entre marginalidade e legitimidade democrática. O seu controle se dá com a superação de suas etapas evolutivas numa relação de causa-efeito, sendo elas, a inquietação, excitação, formalização e institucionalização.

\footnotetext{
${ }^{4}$ Gohn (2000) aponta que foi Lorenz Von Stein, em 1842, o primeiro autor a utilizar o termo "movimento social”, pois sentiu a necessidade de uma ciência da sociedade para estudar o socialismo emergente na França.
} 
Ainda sob influência da teoria da estratificação social da corrente funcionalista parsoniana, Ralph H. Turner e Lewis M. Killian (1957) e Neil Smelser (1963) resgatam a psicologia social de alguns interacionistas simbólicos ao formularem uma teoria dos comportamentos coletivos. Esses autores situam os movimentos sociais como expressão das ações coletivas e derrubam a máxima de que política está vinculada a estrutura social.

Turner e Killian, em seu trabalho Collective Behavior (1957), tratam das características e dos processos que constituem os movimentos sociais, a relação existente com suas normativas, os valores, as relações sociais e os seus significados, como emergentes da interação social e produtores de novas concepções acerca de questões como justiça e injustiça, moralidade e imoralidade, realidade e fantasia etc.

Essa corrente de pensamento ainda aborda questões como controle e poder na organização dos movimentos, espécies de movimentos, dentre eles, os separatistas; e temas como a participação orientada, lideranças e seguidores e produtos dos movimentos.

Questões como continuidade e tradição aparecem como elementos preponderantes para a diferenciação dos movimentos sociais para outras espécies de ações coletivas (Turner \& Killian, 1957), pois garantem ao movimento a definição de objetivos, metas, estratégias e organização estrutural, inclusive com a indicação do papel dos líderes e a formação de uma identidade grupal.

Embora com grande apego as regras baseadas em tradições, os movimentos apresentam um dinamismo próprio que os levaria a institucionalização ou não. A institucionalização de um movimento social apenas é obtida quando esta passa por uma estabilidade interna e ganha notoriedade na sociedade.

A análise de Turner e Killian (1957) foi retomada na década de 90, por Gamson (1992), em sua teoria das "normas emergentes" , e seus estudos serviram de base para a compreensão do comportamento humano racional e emocional, não como figuras opostas, mas sendo possível sua conciliação e, diferentemente de outros teóricos, que viam a mobilização coletiva mais emocional como resultado de instabilidade social. Os primeiros autores entendem que os movimentos sociais podem ser vistos como um processo de construção social em andamento.

Neil Smelser, em sua obra Comportamento coletivo (1963), elabora a teoria da "tensão estrutural", na qual o motivo principal para o surgimento de movimentos sociais está no equilíbrio distorcido de sistemas sociais. Ou seja, a contradição, o conflito e a tensão numa sociedade proporcionam ansiedade e incerteza nos indivíduos; esses querem aliviar esses impactos. Nessas situações, as pessoas tendem a seguirem crenças e valores irracionais para explicarem os fatos sociais.

A não-correspondência entre os valores e as práticas efetivas da sociedade, o bloqueio do funcionamento institucional, elementos disfuncionais desafiando a sobrevivência do sistema são aspectos que podem colocar o sistema social em desequilíbrio e provocar tensões estruturais que, por sua vez, deflagram movimentos sociais.

Smelser (1963) defende que, as massas podem ser definidas como movimentos sem uma meta em particular ou orientados por normas ou valores. As massas orientadas por normas dependem de condições estruturais para criação dessas. As massas orientadas por valores se pautam pela mudança de valores vigentes, o que pode resultar em uma revolução política, uma coletividade em princípio revolucionária, mas contida no sistema político; e, por fim, culminar no desaparecimento do próprio movimento.

As categorias-chave como "comportamento coletivo", "explosões coletivas" e "movimentos coletivos" são adotadas por Smelser (1963) para explicar o fenômeno social do comportamento não-institucionalizado, apresentando como resposta

\footnotetext{
${ }^{5}$ A teoria da norma emergente é um conceito para explicar o comportamento coletivo. Turner e Killian demonstram que as normas que gerem a situação, embora não sejam inicialmente visíveis e perceptíveis para todos os participantes, essas regras surgem através de um processo de interação social, no qual os indivíduos buscam sinais indicadores por meio de suas experiências anteriores. Os autores advertem que algumas pessoas tendem a se sentir constrangidas pela ausência de normas ou clareza na definição destas e tentaram "emergir" para salvaguardar seus valores e conceitos.
} 
para esses comportamentos coletivos desviantes o funcionamento ótimo do sistema social, com base no surgimento de novas crenças e sua interferência nos comportamentos coletivos.

Apesar do fato de o modelo estrutural-funcional alegadamente proporcionar uma teoria causal sobre o surgimento de movimentos sociais, não dá nenhuma explicação precisa sobre como ocorre a passagem do isolamento, tensão e frustração para a ação do movimento. Não se pode presumir que essa passagem seja automática.

Smelser (1963) também é criticado pelo forte apelo a motivação psicológica em sua teoria, por supor que os indivíduos são essencialmente irracionais em suas reações à condições sociais extremas ou difíceis; e, por colocar em segundo plano, a organização e recursos sociais, inclusive na definição dos movimentos sociais.

\section{A teoria organizacional-comportamentalista}

Gohn (2000) afirma que se encontram nos trabalhos de Selzinick (1952), Gusfield (1955) e Messinger (1955) a base teórica para o paradigma organizacional-comportamentalista, com fundamentação na produção weberiana sobre burocracia e na obra de Michells (1959) sobre a lei de ferro das oligarquias. Os autores buscaram essas matrizes para compreender os comportamentos coletivos agrupados em organizações com interesses e objetivos específicos.

Tal como a teoria das sociedades de massas, aquela corrente não criou nenhuma consideração teórica específica sobre os movimentos sociais. Mas induziu a produção de conhecimento sobre a mobilização de recursos, que se configura como uma teoria contemporânea, que será examinada a seguir.

As teorias contemporâneas são representadas pela teoria da Mobilização de Recursos (MR) e pela teoria de Mobilização Política (TMP) ou das Oportunidades Políticas, como era também conhecida.

A teoria da Mobilização de Recursos tem como foco principal a acessibilidade de recursos, humanos, financeiros e de infraestrutura, que permitiriam a viabilidade do movimento social; e a teoria da Mobilização Política enfatizaria as interações e distribuições no âmbito dos movimentos sociais, conforme se vê abaixo.

\section{As Teorias Contemporâneas Norte-Americanas da Ação Coletiva e dos Movimentos Sociais}

As abordagens neoutilitaristas no estudo dos movimentos sociais surgiram nos anos 70; e, desde então, se expandiram rapidamente. De acordo com Gohn (2000, p. 49), foram as transformações políticas que ocorreram nos anos 60 nos Estados Unidos que levaram ao surgimento de uma nova teoria explicativa sobre os movimentos sociais, denominada de corrente da Mobilização dos Recursos.

O pressuposto dessa teoria é que os movimentos sociais se desenvolvem na esteira de uma atividade organizacional consciente, conseguem mobilizar recursos materiais e simbólicos que estão disponíveis, tais como dinheiro, o tempo das pessoas e a legitimidade.

Os movimentos sociais são estudados em termos de oportunidades, estratégias, modos de comunicação e competição com grupos e autoridades que têm interesses opostos. Retirando a ênfase dada pelo paradigma tradicional baseado nos sentimentos e ressentimentos dos grupos coletivos, assim como nas privações materiais e culturais dos indivíduos. Tal raciocínio acrescenta alguns indícios para a compreensão de como surgem os movimentos sociais, mas dificilmente consegue elucidar o significado que as mobilizações sociais coletivas podem ter.

$\mathrm{Na}$ teoria da mobilização dos recursos, o papel das crenças compartilhadas e da identidade coletiva, tratados pelas correntes clássicas enquanto comportamentos irracionais foram rechaçados, dando lugar aos movimentos sociais enquanto grupos de interesses, sob a ótica de organizações, permeados pelos processos de burocracia de uma instituição. O conceitochave da Mobilização dos Recursos é a variável dos recursos: humanos, financeiros, de infraestrutura etc. 
Os movimentos surgem, de acordo com a Mobilização dos Recursos, quando se estruturam as oportunidades políticas para ações coletivas, como também quando as facilidades e as lideranças estão disponíveis.

Os movimentos sociais são analisados a partir da competição pela fonte de recursos junto com os partidos políticos e outros grupos de interesses. Como explicam McCarthy e Zald (1977), a organização de uma ação coletiva é complexa, uma vez que identifica seus objetivos a partir das preferências de um movimento social ou um contramovimento, esforçando-se para praticar aqueles objetivos.

Aspectos culturais são reduzidos a cultura organizacional, sob a tônica macroeconômica, sem atribuir função importante aos indivíduos. As críticas que surgem a Mobilização dos Recursos versam sobre a desconsideração de aspectos importantes da vida social, como valores, reivindicações e ideologia portados pelos atores de cada movimento, que nem sempre constituem escolhas racionais, ou podem ser reduzidas a relações de custo e benefício.

Embora haja entre seus autores quem admita o conteúdo simbólico das demandas dos movimentos sociais (Olson, 1965), esses argumentos acabam desarticulando a relação entre a ideologia do movimento e as tradições discursivas preexistentes, trazidas pelos sujeitos de cada movimento.

O modelo de Mobilização dos Recursos leva em conta, primariamente, "como" os movimentos se formam e se engajam em ação coletiva. Assim, a Mobilização dos Recursos reduz a autonomia dos padrões simbólicos, atribuindo a cultura um caráter meramente instrumental porque os movimentos passam a ser indústrias econômicas (Gonh, 2000, p. 53).

Olson (1965) foi um dos importantes teóricos da Mobilização dos Recursos. Para o autor os benefícios coletivos não eram suficientes para motivar a participação de um ator racional, uma vez que esse poderia se aproveitar dos esforços dos demais, em benefício próprio, diminuindo, assim, seu custo pessoal na aquisição do benefício.

O autor destaca que os incentivos coletivos são a base racional de ações coletivas. Porém, desconsidera a variação na percepção da eficácia da participação em um movimento, tornando, desta forma, seu modelo de ordem eminentemente microeconômica.

Myra M. Ferree, uma das importantes críticas a Mobilização dos Recursos, sustenta que a visão sobre os movimentos sociais é iminentemente burocrática, afirma que a introdução do modelo de racionalidade na Mobilização dos Recursos por Olson torna a teoria microeconômica da escolha racional, “(..) um belo cavalo de troia” (2002, p. 152).

Uma questão fundamental encontra-se na base microeconômica da teoria, que estuda o indivíduo racional como aquele ator capaz de maximizar seus benefícios pessoais e reduzir custos, na expectativa de que os esforços tomados para a aquisição de bens coletivos sejam mínimos; caso contrário, haveria um aumento dessa demanda não esperado do ponto de vista racional. Essa ideia se mostra falaciosa, pois a Mobilização dos Recursos não disponibiliza adequados instrumentos e regras para mensurar as preferências, independentemente das opções, agenciadas por esses atores, cujas opões dependem de suas escolhas.

Na teoria da mobilização dos recursos, a sociedade é vista como um arranjo estático e homogêneo das elites e nãoelites, onde há grupos incluídos e excluídos; o objetivo destes é lutar para se tornarem incluídos pela organização social. Novos canais e novas arenas para a mudança do sistema político vigente não são mencionados na Mobilização dos Recursos. Assim como não se examina o papel dos partidos e dos conflitos ideológicos.

Melucci (2001) ao criticar a natureza objetivista da Mobilização dos Recursos, argumenta que os teóricos deste modelo observam apenas as dimensões externas das lutas dos movimentos, que são relevantes para a competição por poder. Fica implícita a noção de um campo de batalhas, construído através dos polos de repressão/facilitação e oportunidade/ameaça. Nesse sentido, a Mobilização dos Recursos tende à desumanizar os movimentos sociais, uma vez que abandona as diferenças e os conflitos de valores existentes interna e externamente, dando características universais aos atores (Ferree, 2001). 
A teoria da Mobilização Política ${ }^{6}$, por seu turno, foi construída a partir de debates que tiveram com outras teorias, dentre elas a Teoria da Escolha Racional de Olson (1965); a Teoria da Mobilização de Recursos de John McCarthy e Mayer Zald (1973; 1977). Todas bastante criticadas na TMP; críticas às velhas abordagens sobre o collective behavior, herança das abordagens psicossociais que predominaram na primeira metade do século XX (Smelser, 1963).

A corrente da mobilização política conversou também com as teorias culturais e identitárias de autores europeus, tais como, a dos Novos Movimentos Sociais (Touraine, 1985; Melucci, 1994), e com a produção norte-americana sobre os movimentos sociais nos debates sobre as questões estruturas versus ações dos atores (Cohen, 1985).

Enquanto a Mobilização dos Recursos destacou o significado das bases organizacionais, da acumulação de recursos e da coordenação coletiva de atores políticos populares, baseados na centralidade das decisões estratégicas deliberadas para os movimentos sociais, desconsiderando as eventualidades, a emotividade, a plasticidade e as características interativas das políticas dos movimentos; a Teoria da Mobilização Política atribuiu um dinamismo, interação estratégica e resposta ao ambiente político em que estavam inseridos os movimentos sociais.

Criada na matriz norte-americana, assim como a Mobilização dos Recursos, a Teoria do Processo Político apresenta forte ligação com precedentes de origem europeia. Tilly (1975) analisou o movimento revolucionário francês no século XVIII, e os movimentos por reformas na Inglaterra no século XIX. O autor estabeleceu uma sociologia política histórica que articula tradições, apresentando como objetivo central a identificação dos mecanismos que organizam os macroprocessos políticos no Ocidente, através do cotejo entre casos.

Com inclinação marxista, Tilly edita, em 1978, sua obra clássica From mobilization to revolution. Em seus trabalhos, Tilly critica a tradição sociológica clássica por ter solapado o estudo das disputas entre elites da análise dos movimentos populares. Afirma que seu ponto de intersecção é a racionalidade e a lógica compartilhada em uma única classe de fenômenos. Entretanto, seu ponto de distinção é o grau de organização e de uso da violência, vinculado aos parâmetros de origem político ou histórico-cultural.

Outros autores destacaram-se no estudo da TMP e na análise empírica, dentre eles, Tarrow (1993), que estudou o movimento de redemocratização da Itália da segunda metade do século XX, e McAdam que aprofundou o debate sobre os movimentos pelos direitos civis nos Estados Unidos (1982).

Tarrow (1993) elabora o conceito-chave de "estrutura de oportunidades políticas", enquanto parâmetro político, concluindo que as mudanças provocadas nas estruturas ganham dimensões formais e informais do ambiente político, criando ou abrindo novos canais de reivindicações para os movimentos que estão alijados do ambiente político. Assim, essas ações podem permear as instituições políticas e administrativas dando voz às reivindicações da sociedade civil, espaço em que ecoam as crises na coalizão política do poder e conclamam, por vezes, por mudanças nas relações políticas entre o Estado e a sociedade.

Em certas estruturas favoráveis, os grupos insatisfeitos se organizam para expressar suas reivindicações na arena pública. A teoria da mobilização política pressupõe que as ações coordenadas pelos potenciais ativistas são fundamentais para a produção de um ator coletivo; entretanto, os agentes coletivos não são preexistentes. Eles se formam por contraste durante o próprio processo contencioso.

A teoria do processo político acrescenta a cultura como componente para estabelecer as redes de contato. O vínculo se forma através da solidariedade resultante da combinação entre o pertencimento (catness) e a densidade das redes interpessoais, que vinculam os membros do grupo entre si (netness), o que Tilly chama de cat-net (1978).

Todavia, a solidariedade por si só não impulsiona a ação dos atores envolvidos nas redes grupais, caso não possa se utilizar das estruturas de mobilização, ou seja, contar com os recursos formais, como organizações civis, e informais, como

${ }^{6}$ A teoria da Mobilização Política também é conhecida por Tilly (1975) como teoria do Processo Político (TPP). 
redes sociais, que favorecem a organização. Desse modo, a mobilização é um processo pelo qual um grupo cria laços de solidariedade e, ao mesmo tempo, controla as ações do coletivo em razão da utilização dos recursos necessários para sua atuação.

A TMP adota uma estrutura de incentivos e/ou constrangimentos políticos que delimita as possibilidades de escolha dos agentes entre cursos de ação, diante de oportunidades políticas favoráveis. A mobilização se fundamenta num conflito entre partes, atingindo o arcabouço das instituições política, uma vez que o Estado polariza sua atuação contra a sociedade ${ }^{7}$. Esses arranjos são variáveis e dinâmicos, podendo os atores migrarem para uma ou outra posição.

O ponto central da teoria da mobilização política se baseia nas relações firmadas com o Estado, que é o "detentor do poder" e membro da polity, uma vez que detém o controle ou acesso ao governo que rege uma população, incluindo nessas formas de controle/acesso os meios de repressão, e os "desafiantes", cujo campo de influência recai sobre o governo e acesso aos recursos controlados pela polity. O papel de um movimento social é promover uma "interação contenciosa", isto é, ser o canal de comunicação e gerenciar as demandas mútuas entre desafiantes e detentores do poder num cenário litigiosos (Tilly, $1993)^{8}$.

Os movimentos sociais seriam uma forma histórico-cultural de expressão de reivindicações, apresentadas por um repertório9 de ação coletiva, através de comícios, greves, assembleias, passeatas, dentre outros (Tilly, 1978); servindo a diversos atores, locais e temas, enquanto conjunto de formas de ação política disponíveis para os agentes em determinada sociedade.

Nos Estados Unidos, a teoria da mobilização política (TMP) compartilhou espaço com a teoria da Mobilização de Recursos (MR), mas logo a suplantou. Diferentemente na Europa, a primeira, aglutinou uma legião de adeptos, que a aplicaram a inúmeros países e períodos. Na América Latina sua adesão foi modesta. E, no Brasil, foi empregada por Boschi (1987) para explicar o processo de redemocratização vivido no final dos anos 1980.

\section{Considerações Finais}

Neste artigo analisamos as teorias contemporâneas a respeito dos movimentos sociais. Primeiramente, se analisou a Escola de Chicago, que entende que os movimentos sociais são frutos da mudança social, provocada pelo interesse particular de seus mentores; e, via o conflito como algo natural e inevitável, resultado das experiências e culturas dos diferentes membros que compunha o grupo.

Em seguida, se estudou a corrente da sociedade de massas, que compreendia os comportamentos coletivos como resultados de ações desconectadas das condutas tradicionais, gerados pela anomia e pelas privações vividas pelo coletivo.

Nos pensamentos de Seymour Martin Lipset (1950) e Rudolf Heberle (1951), a teoria da ação coletiva foi examinada sob a perspectiva sociopolítica, compreendendo que as classes sociais e as relações sociais de produção deveriam ser categorias a ser estudadas como comportamentos coletivos do tipo político-partidário. Na mesma linha, Heberle (1951) considerava que os movimentos sociais eram o resultado de vontade política do grupo, que buscavam nas elites políticas treinamento e recrutamento para alcançar seus objetivos. Desse modo, os movimentos eram o resultado do descontentamento dos indivíduos com a ordem social vigente e sua meta seria a mudança dessa ordem.

A teoria do sistema social, estudada por Parsons (1951), resultou na concepção funcionalista, e tinha como ideia central a de que os comportamentos coletivos geram os movimentos decorrentes de períodos de inquietação social, incertezas,

\footnotetext{
${ }^{7}$ A proposta de Tilly (1993) é romper com a ideia monolítica de Estado e sociedade, atribuindo a essa equação a noção de "detentores do poder".

${ }^{8}$ Estado e movimentos sociais são formas de ação coletiva, de acordo com Tilly, de origem histórico-estrutural e vinculados a uma teoria da formação do Estado nacional. Os movimentos sociais seriam uma criação ocidental, decorrente de uma série de mudanças estruturais ocorridas no século XVIII, que acarretaram a centralização de poder político, principalmente na Inglaterra.

${ }^{9}$ Para Tilly (1995) o conceito de repertório engloba rotinas compartilhadas através de um processo de escolha, influenciado pela cultura de longa duração.
} 
impulsos reprimidos, ações frustradas, mal-estar e desconfortos sociais, associados ao descontrole e a desintegração dos costumes sociais.

A teoria social tinha por conceito-chave a mudança no comportamento individual. Essa corrente compreendia que os movimentos atuariam num cenário de irracionalidade em oposição à ordem vigente, de modo que a mudança social consubstanciava um sinônimo de sociedade desorganizada, de colapso no sistema social e de desvio social.

Já o paradigma organizacional-comportamentalista teria fundamentação na produção weberiana sobre burocracia e na obra de Michells (1959) sobre a lei de ferro das oligarquias, e buscava compreender os comportamentos coletivos agrupados em organizações com interesses e objetivos específicos.

Por fim, se analisou as teorias contemporâneas da Mobilização de Recursos (MR) e a teoria de Mobilização Política (TMP) ou das Oportunidades Políticas.

Por meio da compreensão das categorias e definição dessas diversas teorias se conclui que a conceituação de movimentos sociais apresenta significados distintos a partir da escolha teórica do leitor. Esses sujeitos/agentes apresentam comportamentos dinâmicos, produtores de reivindicações e de demandas, carregados de valores culturais, denominados pelo autor de "dialética de criação e controle" (Gohn, 2000, p. 143).

Desse modo, se percebe que as características dos movimentos sociais contemporâneos são guiadas para a teoria da ação coletiva, o que implica a revisão de algumas teorias, que poderão associadas as questões identitárias, em especial, àquelas que examinam a criação e politização espaços alternativos de lutas no cenário contemporâneo latino americano, que poderão se expandir para outros diálogos em novos artigos.

\section{Referências}

Boschi, R (1987). A arte da associação. Política de base e democracia no Brasil. Rio de Janeiro: Iuperj/Vértice.

Durkheim, É. (2000). O suicídio. Estudo de Sociologia. In: Causas Sociais e Tipos Sociais. Trad. Monica Stahel, São Paulo: Martins Fontes.

Ferree, M. M., Gamson, W. A., Gerhards, J. \& Rucht, D. (2002). Shaping abortion discourse: democracy and the public sphere in Germany and the United States. New York, Cambridge University Press.

Fromm, E. (1983). O medo à liberdade. Trad. Octávio Alves Velho, 14. ed. Rio de Janeiro: Guanabara Koogan.

Gamson, W. A. (1992). Talking politics. Boston: Cambridge University,

Gohn, M. G. (2000). Teorias dos movimentos sociais. Paradigmas clássicos e contemporâneos. 2. ed. São Paulo: Edições Loyola.

Gusfield, J. R (1955). Social structure and moral reform: A study of the woman's christian temperance union. The American Journal of Sociology, 61(3).

Gusfield, J. R (1996). Contested Meanings: The construction of alcohol problems. University of Wisconsin Press, Madison.

Heberle, R. (1951). Social movements: an introduction to political sociology. New York: Appleton-Century-Crofts.

Hoffer, E. (1951). The True Believer: Thoughts on the nature of mass movements. New York: Harper \& Row.

Kornhauser, W. (1959). The politics of mass society. New York: Free Press.

Le Bon, G. (1954). Psicologia das multidões. Rio de Janeiro: F. Briguet \& Cia.

Lipset, S. M. (1950). Agrarian Socialism: The Cooperative Commonwealth Federation in Saskatchewan. University of California Press.

Marconi, M. A, \& Lakatos, E. V. (2004). Metodologia científica. São Paulo: Editora Atlas.

McCarthy, J. \& Zald, M. (1977, maio). Resource mobilization and social movements: a partial theory. American Journal of Sociology, 82(6), pp. 1212-1241.

McCarthy, J. \& Zald, M. (1973). The trend of social movements in America: Professionalization and resource mobilization. CRSO Working Paper. <http://deepblue.lib.umich.edu/bitstream/2027.42/50939/1/164.pdf>.

Melucci, A. (1989, junho). Um objetivo para os movimentos sociais? Trad. Suely Bastos, Luz Nova, 17 , São Paulo, 49-66. <http://www.scielo.br/pdf/ln/n17/a04n17.pdf>.

Melucci, A. (2001). A invenção do presente. Movimentos sociais nas sociedades complexas. Petrópolis/RJ: Vozes. 
Research, Society and Development, v. 10, n. 9, e56510918601, 2021

(CC BY 4.0) | ISSN 2525-3409 | DOI: http://dx.doi.org/10.33448/rsd-v10i9.18601

Merton, R. K. (1949). Social theory and social structure. Illinois: Glencoe .

Negri, A. (2009). Para uma definição ontológica da multidão. Lugar Comum, n.19-20, p. 15-26. <http://uninomade.net/wpcontent/files_mf/113003120823Para\%20uma\%20defini\%C3\%A7\%C3\%A3o\%20ontol\%C3\%B3gica\%20da\%20multid\%C3\%A3o\%20-

$\% 20$ Antonio\%20Negri.pdf>.

Nevado, P. (2008). Popper e a investigação: a metodologia hipotética-dedutiva.

Olson, M. (1965). The logic of collective action. Public goods and the theory of groups. Cambridge: Harvard University Press.

Parsons, T. (1951). The social system. Glencoe: The Free Press.

Pereira, A. S., Shitsuka, D. M., Parreira, F. J. \& Shitsuka, R. (2019). Metodologia da pesquisa científica [e-book], Santa Maria, RS: UFSM, NTE, 2018. https://www.ufsm.br/app/uploads/sites/358/2019/02/Metodologia-da-Pesquisa-Cientifica_final.pdf

Smelser, N. (1963). The sociology of economic life. Englewood Cliff: Printice-Hall.

Stein, L. V. (1842). Der Sozialismus und Kommunismus des hetitigen Frankreich. Eir. Beitrag zur Zeitgeschichte: Leipzig, XII.

Tarrow, S. (1993). Contentious repertoires in Great Britain. Social Science History, 17, 1758-1834.

Tilly, C. (1995). Contentious repertoires in Great Britain, In: Traugott, Mark (org.). Repertoires and cycles of collective action. Durham, NC: Duke University Press, 15-42.

Tilly, Charles (1993). Social movement as historically specific clusters of political performances. Berkeley Journal of Sociology, 38, pp. 1-30.

Tilly, C. (1978). From mobilization to revolution. Boston: Wesley Publishing Co.

Tönnies Becker, H. (1996). A Escola de Chicago. Mana [online] 2(2), 177-188. <http://www.scielo.br/scielo.php?pid=S0104-9313199600020000 $8 \&$ script $=$ sci_arttext>

Touraine, A. (1985). The study of social movements. Social Research, 52(4), pp. 749-787.

Turner, R. H. \& Killian, L. M (1957). Collective behavior. Nova York, Prentice-Hall, Inc. 197. 